\title{
RANCANG BANGUN APLIKASI REMINDER PENGUMPULAN SOAL UJIAN DI SMK JAKARTA 1 BERBASIS WEB
}

\author{
Harni Kusniyati ${ }^{1}$, Arum Waruju Jono Putro ${ }^{2}$ \\ Jurusan Teknik Informatika, Fakultas Ilmu Komputer, Universitas Mercu Buana ${ }^{1,2}$ \\ Jl. Raya Meruya Selatan, Kembangan, Jakarta 11650 \\ E-mail : harni.kusniyati@mercubuana.ac.id ${ }^{1}, 41514010105 @$ student.mercubuana.ac.id ${ }^{2}$
}

\begin{abstract}
ABSTRAK
Ujian merupakan suatu tes yang digunakan untuk menilai pelajaran yang telah diberikan oleh guru kepada murid - muridnya dalam jangka waktu tertentu. Sebelum kegiatan ujian semester dimulai biasanya masing - masing guru bidang studi akan diharuskan untuk membuat soal yang kemudian diserahkan ke pihak panitia penyelenggara semesteran. Untuk membantu panitia dalam menyampaikan informasi ke masing - masing guru dan mengingatkan guru untuk mengumpulkan soal ujian maka dibutuhkan suatu Reminder atau pengingat. Dimana Reminder sendiri merupakan fitur pesan yang dapat membantu untuk mengingatkan sesuatu pada waktu tertentu. Aplikasi Reminder menjadi salah satu alternatif untuk membantu panitia dan menjadi pengingat setia bagi guru agar lebih mudah digunakan dan mudah diakses kapan dan dimana saja. Pada penilitian ini penulis akan membuatkan aplikasi reminder pengumpulan soal ujian di SMK Jakarta 1 dengan menggunakan bahasa pemrograman PHP dilengkapi dengan notifikasi ke email guru dan panitia, serta dibuatkan perancangan alur proses menggunakan UML (Unified Modeling Language).
\end{abstract}

Kata kunci : Ujian, Reminder, Aplikasi Reminder

\begin{abstract}
The exam is a test to given to assess the lessons that have given by a teacher to student in a period of time. Usually almost every six months the school always organizing the exam like the midterm or the final exams for one semester. Before the semesters started usually a teacher the result are wired to make about submitted to the biannual the organizing committee .To help the committee in conveying information to each teachers and remind teachers to collect the exam questions then a reminder is needed. Reminder is a messaging feature that can help to remind something at a certain time. Reminder application becomes one of the alternatives to help the committee and become a faithful remind for the teacher to make it easy to use to access anywhere and anytime. In this research, the writer will make reminder application to collect test questions in SMK Jakarta 1 by using PHP programming language with notification to teacher's email and committee, and design process flow using UML (Unified Modeling Language).
\end{abstract}

Keyword : Exam, Reminder, Reminder Application 


\section{PENDAHULUAN}

Sekolah menengah kejuruan (SMK) Jakarta 1 berdiri pada tahun 1983. Hampir setiap enam bulan sekali sekolah SMK Jakarta 1 selalu mengadakan ujian semester yang bertujuan untuk menilai atau mengetahui hasil belajar siswa di SMK Jakarta 1 selama satu semester. Sebelum kegiatan semesteran dimulai biasanya masing - masing guru bidang studi diharuskan untuk membuat soal yang kemudian diserahkan ke pihak panitia. Biasanya pihak panitia akan memberikan informasi mengenai kapan guru harus mengumpulkan soal ujian dan batas waktu paling lambat untuk mengumpulkan soal ujian. Setelah memberikan informasi kepada guru, maka panitia akan mengecek satu persatu guru yang telah mengumpulkan soal. Jika dalam proses pengumpulan soal ujian dibantu sebuah sistem aplikasi yang dapat melakukan validasi pengumpulan soal ujian serta pengiriman notifikasi maka dapat mempermudah guru dalam proses pengumpulan soal dan menerima informasi. Pada proses pembuatan aplikasi reminder pengumpulan soal ujian, penulis menggunakan bahasa pemrograman PHP (Hypertext Preprocessor) yang digunakan sebagai media interaksi proses terhadap data di database.

\section{LANDASAN TEORI}

\subsection{Pengertian Aplikasi}

Perangkat lunak aplikasi adalah suatu subkelas perangkat lunak komputer yang memanfaatkan kemampuan komputer langsung untuk melakukan suatu tugas yang diinginkan pengguna. Biasanya dibandingkan dengan perangkat lunak sistem yang mengintegrasikan berbagai kemampuan komputer, tapi secara tidak langsung menerapkan kemampuan tersebut untuk mengerjakan suatu tugas yang menguntungkan pengguna. Contoh utama perangkat lunak aplikasi adalah pengolah kata, lembar kerja dan pemutar media (Jurnal Sistem Informasi. 2011. Muhammad Wyzer et al).

\subsection{Pengertian Reminder}

Pengertian reminder adalah sebuah pesan yang menolong seseorang untuk mengingat sesuatu. Reminder dapat lebih bermanfaat ketika informasi kontekstual digunakan untuk menyajikan informasi pada waktu yang tepat dan tempat yang tepat. Reminder dapat digunakan sebagai manajemen waktu yang berfungsi untuk member alarm peringatan berupa pemberitahuan berbasis lokasi, waktu maupun catatan yang berupa kontekstual (Jurnal SENTIKA. 2016. Kosidin \& Resha $\mathrm{Nu}$ Farizah).

\subsection{Basis Data}

Basis data merupakan kumpulan data yang berhubungan secara logis dan deskripsi data tersebut, yang dirancang untuk memenuhi informasi yang dibutuhkan oleh suatu organisasi (Indrajani, S.Kom., MM, 2001: 2). Pada kajian ini bertujuan untuk proses penguploadan soal dan pembuatan reminder dapat tersimpan pada database.

\section{$2.4 \mathrm{MySQL}$}

MySQL merupakan sebuah program pembuat database yang bersifat open source, artinya siapa saja boleh menggunakannya dan tidak dicekal (Bunafit Nugroho, 2004 : 29). Pada aplikasi reminder pengumpulan soal ujian, database ini sangat berguna untuk menyimpan semua proses data.

\subsection{PHP}

PHP (Hypertext Preprocessor) adalah sebuah bahasa pemrograman web berbasis server (server-side) yang mampu memparsing kode PHP dari kode web dengan ekstensi .php, sehingga menghasilkan tampilan website yang dinamis (Edy Winarno ST, M. Eng, 2014 : 49). Pada aplikasi reminder pengumpulan soal ujian, bahasa pemrograman ini sangat dibutuhkan untuk proses bisnis seperti alur data penyimpanan hingga validasi. 


\subsection{Penelitian Terdahulu}

Terdapat beberapa penelitian terdahulu yang memiliki keterkaitan dengan penelitian yang peneliti lakukan.

1. Penelitian yang dilakukan oleh Kosidin dan Reisha Nur Farizah (2016) dengan judul PEMODELAN APLIKASI MOBILE REMINDER BERBASIS ANDROID. Seminar Nasional Teknologi Informasi dan Komunikasi (SENTIKA). Pada penelitian ini penulis bertujuan sebagai sarana penunjang informasi terkait pengingat agenda kerja.

2. Penelitian yang dilakukan oleh Sitepu, Ridwan (2012) dengan judul PERANCANGAN SISTEM OTOMATISASI PENGINGAT BATAS WAKTU PINJAMAN BUKU DI PERPUSTAKAAN KOTA YOGYAKARTA MELALUI LAYANAN SMS GATEWAY. JUrnal Teknologi Informasi. Pada penelitian ini sebagai sarana untuk meningkatkan kesadaran para anggota untuk mengembalikan buku ketika masa berlaku peminjaman hampir habis.

Dapat disimpulkan bahwa penelitian diatas memiliki persamaan dengan penelitian yang dilakukan oleh penulis, yaitu membahas mengenai reminder. Perbedaannya penulis mengaplikasikan reminder dalam bidang pendidikan. Khususnya untuk mengefektifkan proses remindering dalam mengumpulkan soal ujian yang dilakukan oleh guru di SMK Jakarta 1. Selain itu dapat memudahkan panitia dalam penyebaran informasi pengumpulan soal dan penerimaan informasi mengenai soal - soal ujian yang telah terkumpul.

\subsection{Pengujian Black Box}

Pengujian black-box berfokus pada persyaratan fungsional perangkat lunak. Dimana pengujian ini memungkinkan perekayasa perangkat lunak mendapatkan serangkaian kondisi input yang sepenuhnya menggunakan semua persyaratan fungsional untuk suatu program (Roger S. Pressman, Ph.D., 2002: 551). Pengujian ini dimaksudkan untuk menemukan kesalahan dan mengetahui apakah fungsi - fungsi masukan dan keluaran dari perangkat lunak sesuai dengan spesifikasi yang dibutuhkan. Tujuan metode ini mencari kesalahan - kesalahan pada :

1. Fungsi yang salah atau hilang

2. Kesalahan pada interface

3. Kesalahan pada struktur data atau akses database

4. Kesalahan performansi

5. Kesalahan inisialisasi dan tujuan akhir

\section{METODOLOGI PENELITIAN}

Jenis metode penelitian yang digunakan penulis untuk menganalisa proses bisnis ialah metode penelitian prediksi karena metode penelitian ini digunakan dengan tujuan untuk menganalisa proses bisnis dimasa yang akan datang.

\subsection{Metode Pengumpulan Data}

Metode pengumpulan data yang digunakan penulis sebagai analisa proses bisnis meliputi:

1) Dokumentasi

Melakukan pengumpulan data dengan mengunjungi tempat objek penelitian dan meminta izin untuk mengambil data yang dibutuhkan dalam penelitian ini.

2) Studi Pustaka

Kajian yang dilakukan dengan membaca buku-buku, jurnal, dan forum - forum di web sebagai literatur informasi yang berhubungan dengan penelitian.

\subsection{Metode Pengembangan \& Perancangan}

\section{Model Waterfall}

Jenis metode pengembangan dan perancangan sistem Waterfall merupakan metode yang klasik dengan memilih pengembangan perangkat lunak yang sistematis dan berurutan, dimulai dari 
tingkat perancangan dalam membangun suatu sistem atau software. Alasan penulis memilih metode ini karena proses pengembangan model ini sederhana dengan menganalogikan air yang mengalir dari tempat tertinggi hingga ke tempat yang lebih rendah artinya bahwa sebuah proses baru bisa dilanjutkan setelah satu tahap awal selesai dengan sempurna.

Model air terjun (waterfall) sering juga disebut model sekuensial linear atau alur hidup klasik. Model ini menyediakan pendekatan kepada perkembangan perangkat lunak yang sistematik dan sekuensial yang dimulai pada tingkat analisis, desain, kode, pengujian dan pemeliharaan (Roger S. Pressman, Ph.D, 2011 : 36). Berikut ini merupakan gambaran dari sekuensial linear / model waterfall :

1. Analisis Kebutuhan Perangkat

Proses pengumpulan kebutuhan dilakukan secara intensif untuk menspesifikasikan kebutuhan perangkat lunak agar dapat dipahami perangkat lunak seperti apa yang dibutuhkan oleh user. Spesifikasi kebutuhan perangkat lunak pada tahap ini perlu untuk didokumentasikan.

2. Desain

Desain perangkat lunak adalah proses multi langkah yang berfokus pada desain pembuatan program perangkat lunak termasuk struktur data, arsitektur perangkat lunak, representasi antarmuka, dan prosedur pengodean. Desain perangkat lunak yang dihasilkan pada tahap ini juga perlu didokumentasikan.

3. Pembuatan Kode Program

Desain harus ditranslasikan ke dalam program perangkat lunak. Hasil dari tahapan ini adalah program komputer sesuai dengan desain yang telah dibuat pada tahapan desain.

4. Pengujian

Pengujian fokus pada perangkat lunak secara dari segi lojik dan fungsional dan memastikan bahwa semua bagian sudah diuji. Hal ini dilakukan untuk meminimalisir kesalahan (error) dan memastikan keluaran yang dihasilkan sesuai dengan yang diinginkan.

5. Pendukung atau Pemeliharaan

Tidak menutup kemungkinan sebuah perangkat lunak mengalami perubahan ketika sudah dikirimkan ke user. Perubahan bisa terjadi karena adanya kesalahan yang muncul dan tidak terdeteksi saat pengujian atau perangkat lunak harus beradaptasi dengan lingkungan baru. Tahap pendukung atau pemeliharaan dapat mengurangi proses pengembangan mulai dari analisis spesifikasi untuk perubahan perangkat lunak yang sudah ada, tapi tidak untuk membuat perangkat lunak terbaru.

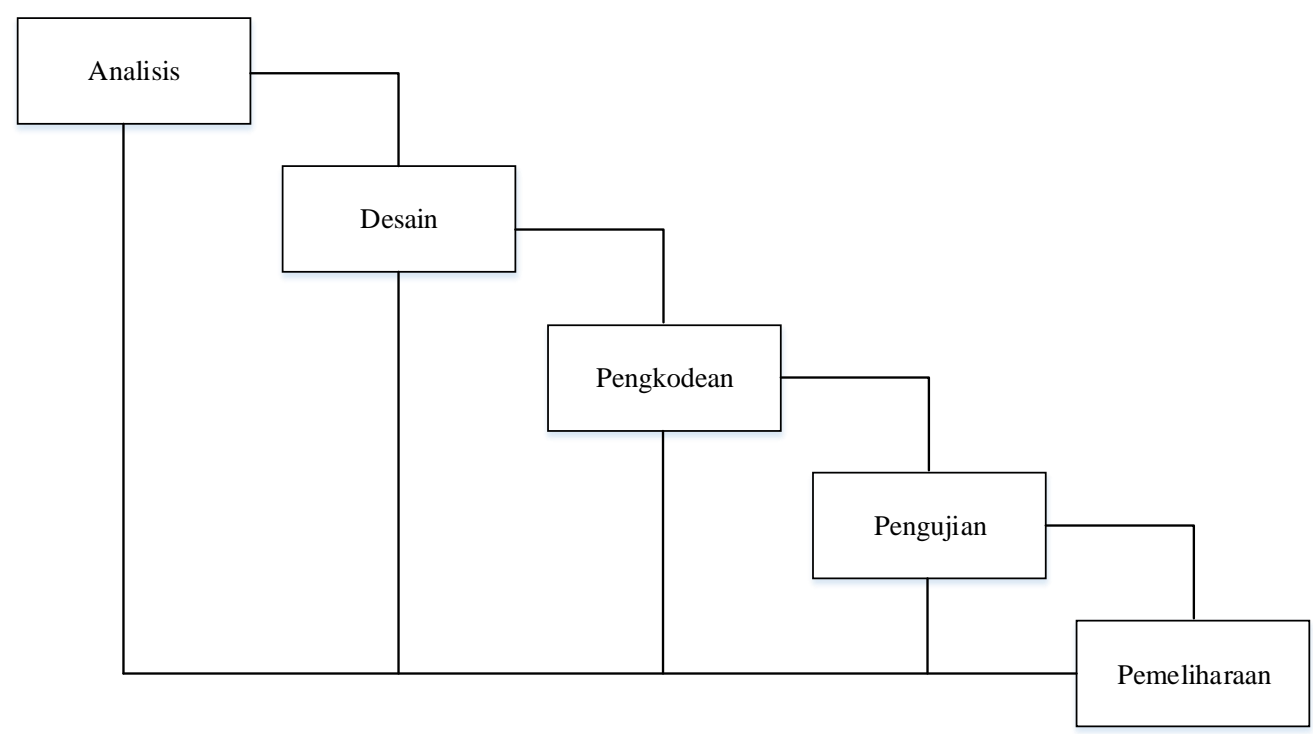

Gambar 1. Model Waterfall 


\section{JURNAL PETIR}

Vol. 11, No. 2, September 2018, P-ISSN 1978-9262, E-ISSN 2655-5018

\section{HASIL DAN PEMBAHASAN}

\subsection{Analisa Sistem Berjalan}

Sekolah Menengah Kejuruan (SMK) Jakarta 1 adalah sekolah yang bertaraf nasional, dimana kegiatan belajar mengajar diarahkan untuk membina siswa-siswinya agar menguasai program pembelajaran yang telah ditetapkan. Untuk mengetahui sejauh mana kemampuan siswa-siswinya dalam menerima pelajaran yang telah diberikan maka perlu dilakukan suatu usaha penilaian atau ujian terhadap hasil belajar siswa. Sebelum kegiatan ujian dimulai biasanya masing - masing guru bidang studi diharuskan untuk membuat soal yang kemudian dikumpulkan atau diserahkan ke pihak panitia.

Akan tetapi, saat ini proses pengumpulan soal di SMK Jakarta 1 masih tergolong manual yaitu dengan cara guru datang langsung ke sekolah untuk memberikan soal baik itu dalam bentuk soft copy atau hard copy. Kemudian pengecekan soal yang dilakukan secara konventional yaitu dengan cara mengecek satu persatu guru yang telah mengumpulkan soal.

Berikut flowchart pengumpulan soal ujian pada sistem berjalan saat ini :

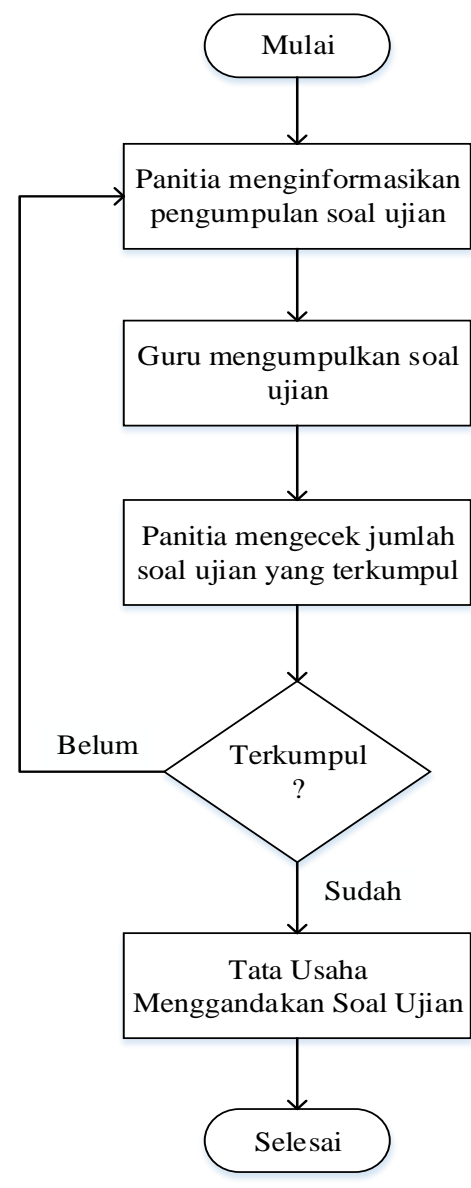

Gambar 2. Flowchart sistem yang berjalan

Berikut deskripsi alur proses pengumpulan soal ujian yang dilakukan di SMK Jakarta 1 :

1. Panitia menginformasikan pengumpulan soal ujian.

2. Guru mengumpulkan soal ujian

3. Panitia melakukan pengecekan soal ujian yang sudah terkumpul

a. Jika hasil pengecekan valid, maka panitia akan menyerahkan soal ke Tata Usaha (TU).

b. Jika tidak maka panitia akan kembali menginformasikan kepada guru

4. Tata Usaha menggandakan soal ujian 


\subsection{Alur Sistem User}

\section{Use Case Guru}

Pada hal ini terdapat rancangan use case untuk interaksi aktor guru dalam melakukan pengumpulan soal yang dimuat pada gambar 3 sebagai berikut.

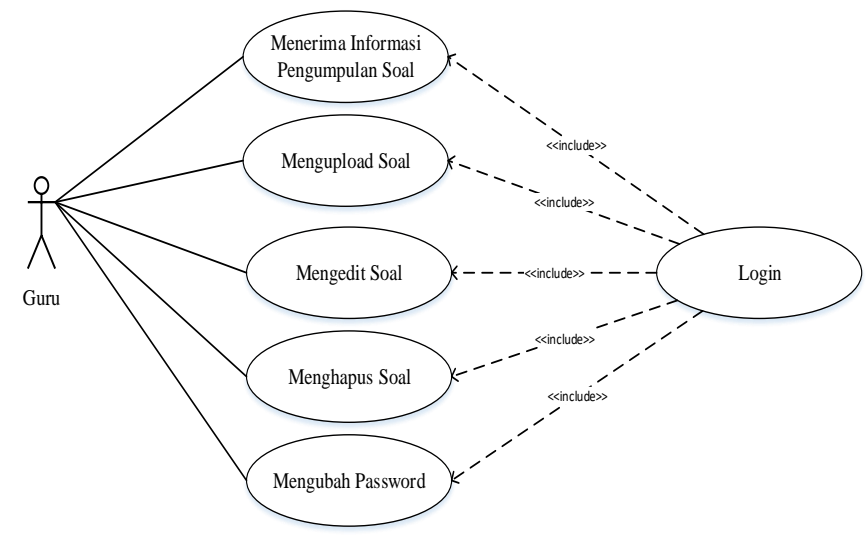

Gambar 3. Use Case User Guru

\section{Use Case Panitia}

Pada hal ini terdapat rancangan use case untuk interaksi aktor panitia dalam melakukan reminder pengumpulan soal yang dimuat pada gambar 4 sebagai berikut.

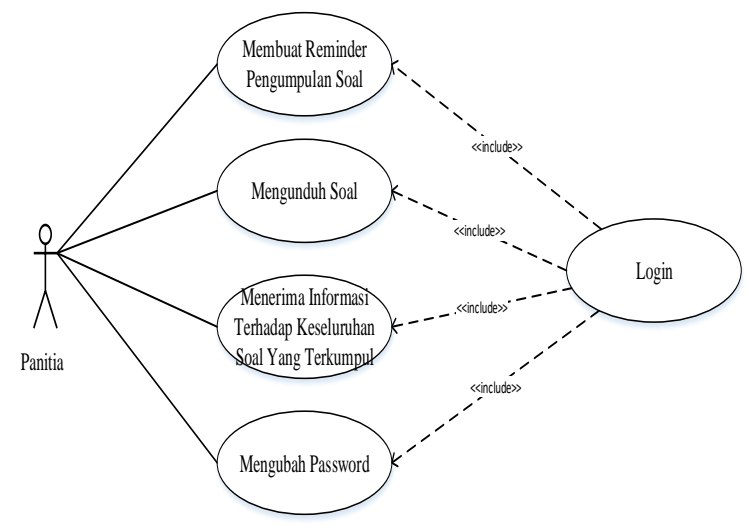

Gambar 4. Use Case User Panitia

\section{Use Case Admin}

Pada hal ini terdapat rancangan use case untuk interaksi aktor admin dalam memilih panitia semesteran dan menambah data guru yang dimuat pada gambar 5 sebagai berikut.

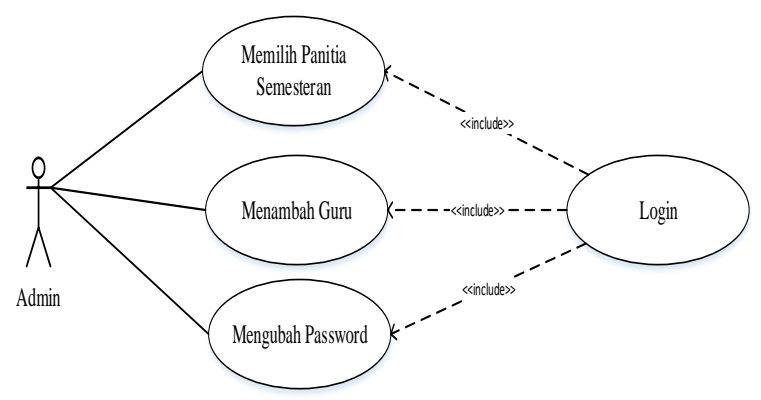

Gambar 5. Use Case User Admin 


\section{Use Case Task Scheduler Windows}

Pada hal ini terdapat rancangan use case untuk interaksi aktor task scheduler dalam memeriksa waktu pengiriman email yang dimuat pada gambar 6 sebagai berikut.

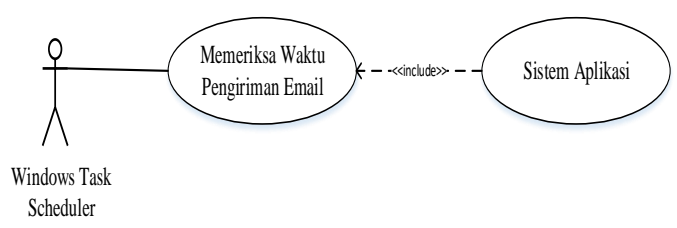

Gambar 7. Use Case Windows Task Scheduler

\section{Activity Guru}

Berikut merupakan activity guru yang mendeskripsikan alur untuk mengupload soal ujian pada aplikasi reminder pengumpulan soal ujian.

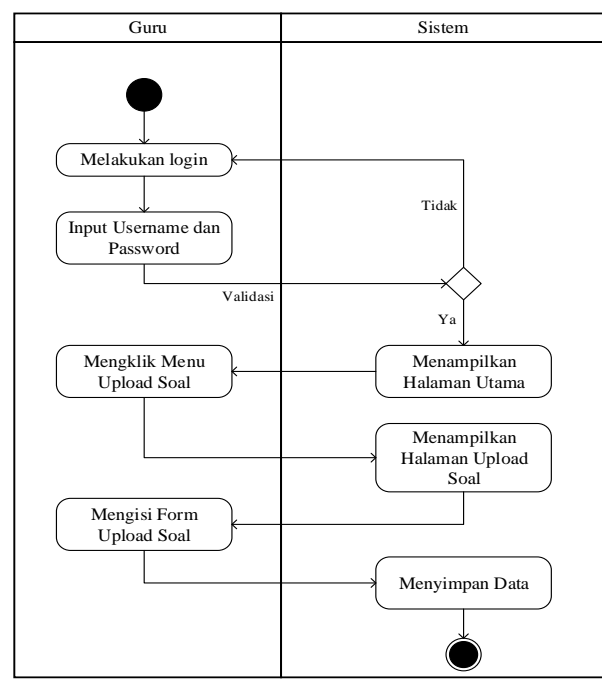

Gambar 8. Activity Guru Untuk Mengupload Soal Ujian

\section{Activity Panitia}

Berikut merupakan activity panitia yang mendeskripsikan alur untuk membuat reminder pada aplikasi reminder pengumpulan soal ujian.

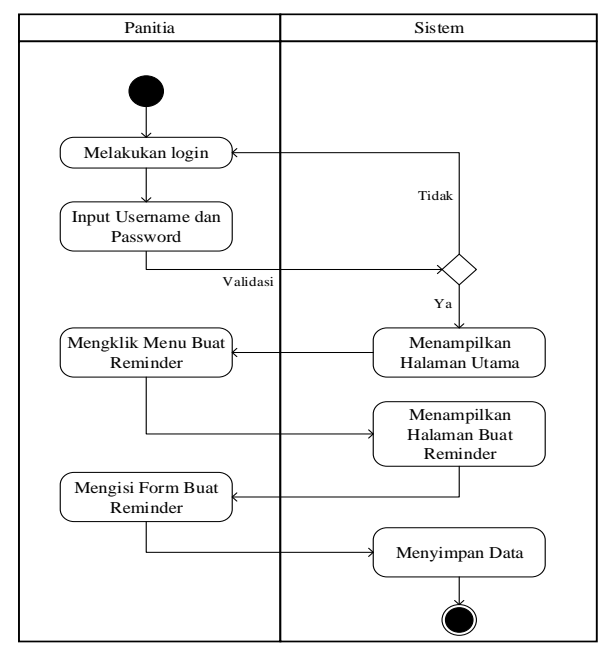

Gambar 9. Activity Panitia Untuk Membuat Reminder 


\section{Activity Task Scheduler}

Berikut merupakan activity task scheduler yang mendeskripsikan alur untuk memeriksa tanggal pengiriman email pada aplikasi reminder pengumpulan soal ujian.

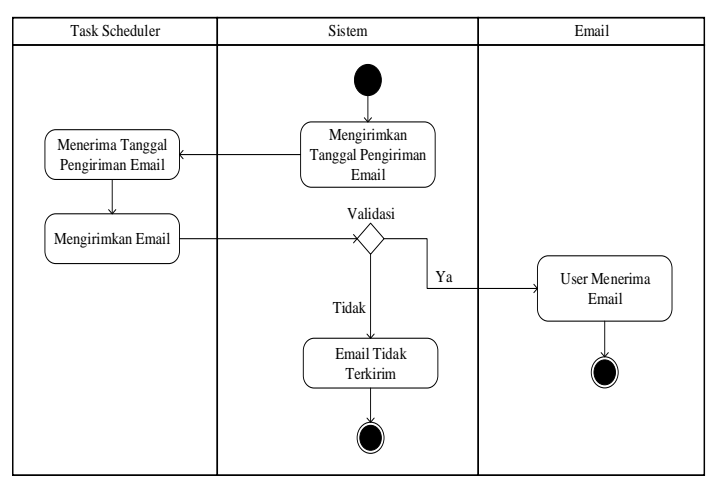

Gambar 9. Activity Task Scheduler Untuk Memeriksa Tanggal Pengiriman Email

\subsection{Perancangan Antar Muka}

\section{Index Utama}

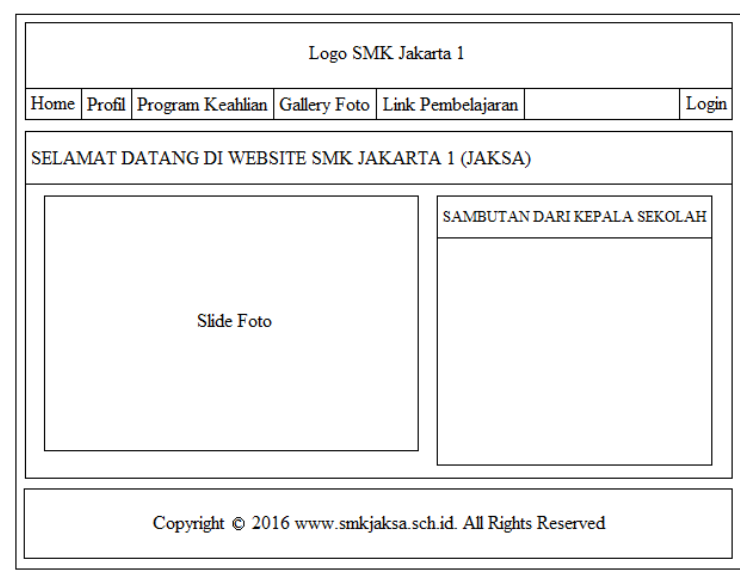

Gambar 10. Rancangan Antar Muka Halaman Index Utama

\section{Login}

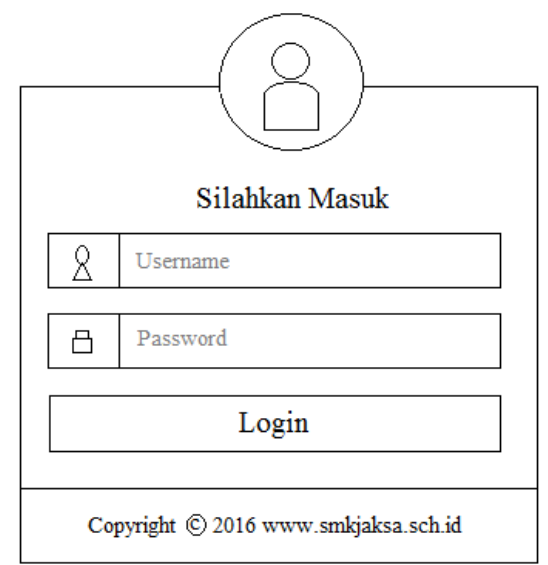

Gambar 11.Rancangan Antar Muka Halaman Login 


\section{Upload Soal}

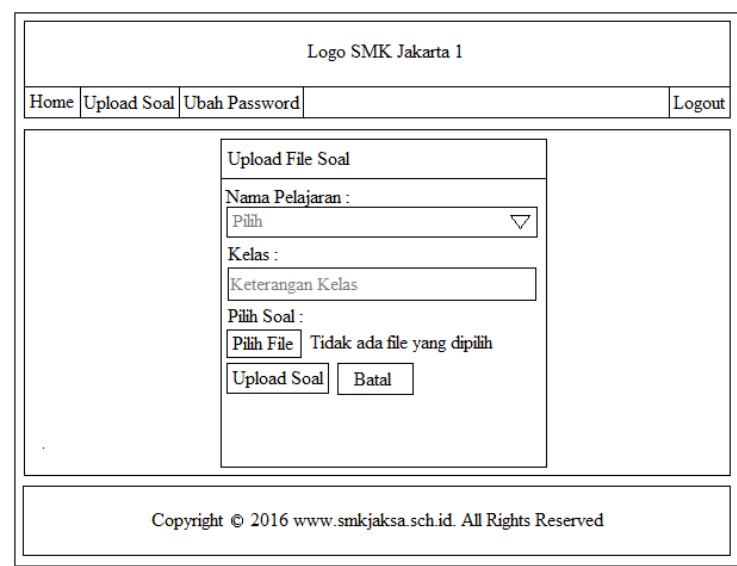

Gambar 12. Rancangan Antar Muka Halaman Upload Soal

\section{Buat Reminder}

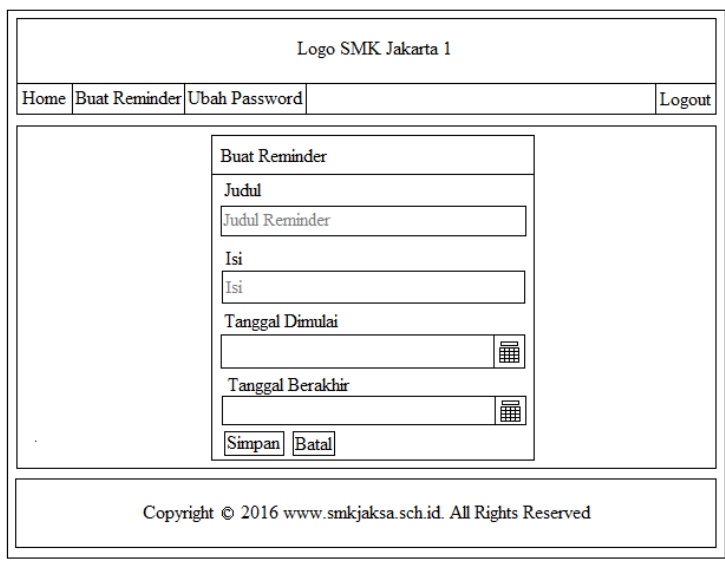

Gambar 13. Rancangan Antar Muka Halaman Buat Reminder

\subsection{IMPLEMENTASI}

Implementasi merupakan tahapan dalam membangun suatu perangkat lunak atau aplikasi untuk menerjemahkan rancangan - rancangan hasil analisa - analisa yang telah dilakukan kedalam bentuk bahasa pemrograman yang berupa sintaks kode sehingga menjadi sebuah aplikasi.

Tujuan dari implementasi sendiri ialah untuk mengetahui apakah proses - proses yang dijalankan pada aplikasi dapat bekerja dengan baik, sehingga tidak terjadi banyak kesalahan kesalahan secara fungsional atau proses yang menyebabkan aplikasi tidak berjalan dengan semestinya.

\subsubsection{Implementasi Antar Muka}

\section{Halaman Beranda}




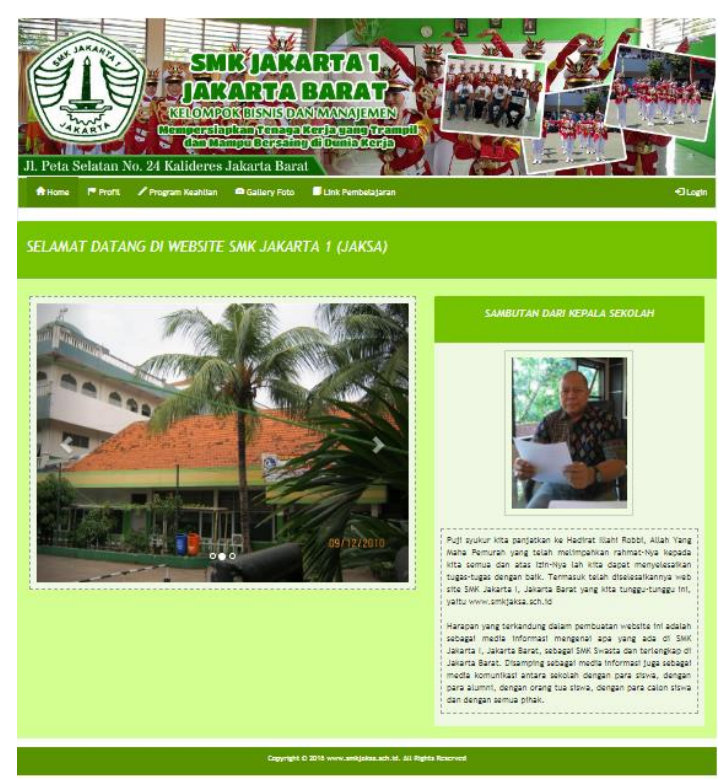

Gambar 14. Halaman Beranda Web Aplikasi

\section{Halaman Upload Soal}

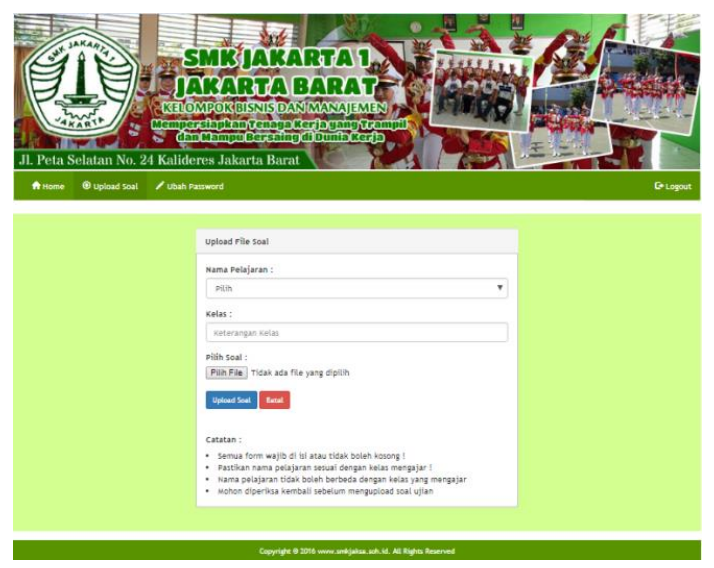

Gambar 14. Halaman Upload Soal

Skrip kode halaman upload soal :

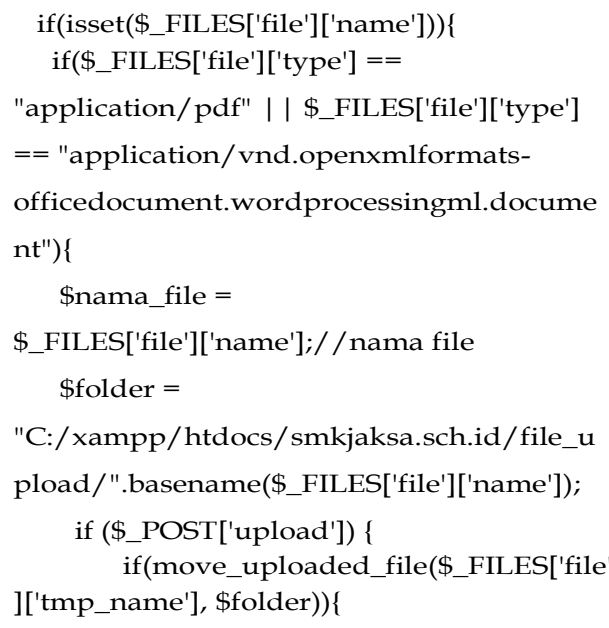




\section{Halaman Buat Reminder}

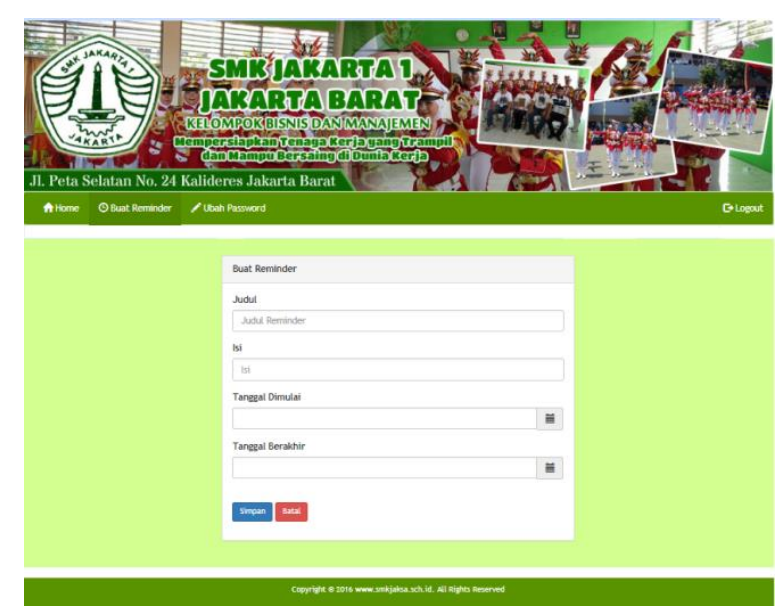

Gambar 15. Halaman Buat Reminder

Skrip kode halaman buat reminder :

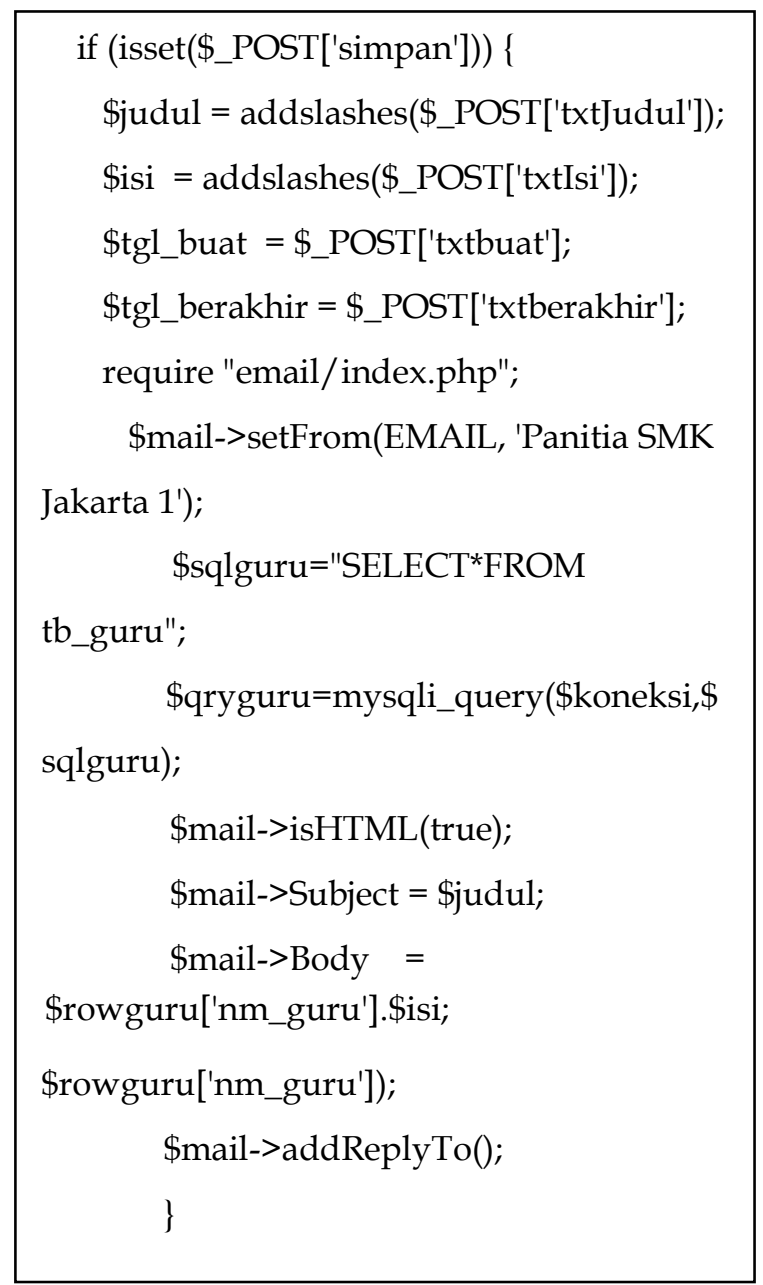




\section{KESIMPULAN DAN SARAN}

\subsection{Kesimpulan}

Kesimpulan yang didapat dari keseluruhan pembahasan yang dilakukan adalah sebagai berikut :

1. Aplikasi ini dapat melakukan upload soal, membuat reminder, menerima notifikasi berupa pop up atau email serta memilih pantia semesteran yang dapat dilakukan pada akun guru, panitia atau admin.

2. Aplikasi ini juga dapat menjalankan reminder sesuai dengan tanggal reminder tersebut dimulai dan berhenti sesuai dengan tanggal reminder tersebut berakhir.

3. Aplikasi ini belum dapat melakukan penyeleksian dalam pengiriman email kepada guru yang sudah mengumpulkan soal.

\subsection{Saran}

Adapun saran untuk kedepannya adalah sebagai berikut :

1. Dalam aplikasi ini belum terdapat halaman informasi detail guru diharapkan kedepannya dapat ditambahkan halaman tersebut.

2. Pada aplikasi ini diharapkan kedepannya dapat melakukan edit dan hapus pada reminder yang telah dibuat.

3. Aplikasi berbasis web ini diharapkan kedepannya dapat bermanfaat dan dikembangkan menjadi aplikasi berbasis mobile.

\section{DAFTAR PUSTAKA}

[1] A.S, Rosa dan M. Shalahuddin. 2013. Rekayasa Perangkat Lunak Terstruktur dan Berorientasi Objek, Bandung: Informatika Bandung.

[2] Indrajani, S.Kom., MM. 2014. Database Systems Case Study All In One, Jakarta: PT Elex Media Komputindo.

[3] Irna Rahayu, dkk. 2015. Implementasi Kamus Kedokteran Dengan Metode Interpolasi (Interpolation) dan Mencari Kemiripan Kata Menggunakan Algoritma Levenshtein Distance Pada Perangkat Android, Jurnal semanTIK.

[4] Kerendi, Dadan. 2015. Membuat CMS Multifitur, Jakarta: PT Elex Media Komputindo.

[5] Khairul, Fahmi dkk. 2016. Perancangan Dan Implementasi Aplikasi Perpustakaan Berbasis Multitenant, Jurnal Informatika Mulawarman.

[6] Kosidin dan Resha Nur Farizah, 2016. Pemodelan Aplikasi Mobile Reminder Berbasis Android, Jurnal SENTIKA.

[7] Masrur, Mukhamad. 2016. Pemrograman Web Dinamis Menggunakan Java Server Pages Dengan Database Relational MYSQL, Yogyakarta: C.V ANDI OFFSET (Penerbit ANDI).

[8] Ngoen, Thomson Susabda. Pengantar Algoritma dengan Bahasa C. 2006. Jakarta: Salemba Teknika.

[9] Nugroho, Andi. Aplikasi Web Informasi Dan Registrasi Peserta Seminar, Workshop, Talkshow Pada Acara Seminar Nasional Pengamplikasian Telematika (SINAPTIKA) Tahun 2016. 2017. Jakarta: SESINDO.

[10] Nugroho, Andi dan Retno Setya Wulandary. Pengelolaan Presensi Dan Gaji Asisten Lab Berbasis WEB Di Fasilkom Universitas Mercu Buana. 2016. Jakarta: Jurnal Ilmiah FIFO.

[11] Sitepu, Ridwan, 2012. Perancangan Sistem Otomatisasi Pengingat Batas Waktu Peminjaman Buku Di Perpustakaan Kota Yogyakarta Melalui Layanan SMS Gateway, Jurnal Teknologi Informasi.

[12] Sudijono, Anas, 2008. Pengantar Evaluasi Pendidikan, Jakarta: Raja Grafindo Persada.

[13] S.Pressman, Roger. 2002. Rekayasa Perangkat Lunak Pendekatan Praktisi (Buku I). Andi and Mc-Graw-Hill Book Co.Indonesia.

[14] Winarno, Edy dkk. 2014. Pemrograman Web Berbasis HTML5, PHP, \& JavaScript, Jakarta: PT Elex Media Komputindo. 